\title{
PARÂMETROS PARA INCLUSÃO SOCIAL E AUTONOMIA DE IDOSOS EM CENTROS DE CONVIVÊNCIA E HABITAÇÃO
}

\author{
CARVALHO, Juliana Araújo \\ Universidade Potiguar - UnP, Graduada em Arquiteta e Urbanista \\ e-mail:julianaraujocarvalho@gmail.com
}

\begin{abstract}
RESUMO
A pesquisa apresenta conceituação teórica e de legislação acerca da inclusão social de idosos em espaços de habitação e lazer. Somando-se a isso, a realização de estudos e visitas técnicas a edificações construídas, a fim de observar as condições atuais e futuras das expectativas das pessoas da terceira idade relacionada à independência da realização de atividades e obrigações do dia-a-dia com conforto, bem-estar e autonomia, relacionadas a NBR 9050/2015; as definições de ambiência e humanização; a influência das boas condições de saúde e da socialização.
\end{abstract}

Palavras chave: acessibilidade; idosos; inclusão.

\begin{abstract}
The research presents theoretical conception and legislation about the social inclusion of the elderly in housing and leisure spaces. In addition to this, studies and technical visits to built buildings, in order to observe the current and future conditions of the expectations of the elderly people related to the independence of carrying out activities and obligations of the day to day with comfort, well-being and autonomy, related to NBR 9050/2015; the definitions of ambience and humanization; the influence of good health conditions and socialization.
\end{abstract}

Keywords: accessibility; seniors; inclusion.

\section{INTRODUÇÃO}

De acordo com estudos do Instituto Brasileiro de Geografia e Estatística (IBGE), até 2050 a população de idosos deve triplicar no Brasil, ou seja, a população com 60 anos ou mais, chegará a 66,5 milhões - 29,3\% do total - até metade do século, o que exigirá demasiadas alterações nas políticas públicas de saúde, previdência, bem como na fiscalização de ambientes com a proposta do desenho universal.

Também, conforme a Sociedade Brasileira de Geriatria e Gerontologia (SBGG) em uma carta aberta à população brasileira, apesar de avanços como a aprovação do Estatuto do Idoso - que de acordo com o art. $2^{\circ}$ e art. $3^{\underline{a}}$, o idoso goza de todos os direitos fundamentais inerentes à pessoa humana; bem como é obrigação da família, da comunidade, da sociedade e do Poder Público, assegurar ao idoso a efetivação do direito à vida, à saúde, à alimentação, à educação, à cultura, ao esporte, ao lazer, à cultura, ao trabalho, à cidadania, à liberdade, à dignidade, ao respeito e à convivência familiar e comunitária - a realidade é que os direitos e necessidades dos idosos ainda não são absolutamente atendidos. 
Ainda mais, tratando-se do Sistema Único de Saúde (SUS), este ainda não está preparado para amparar adequadamente esta situação. Ou seja, ainda prevalecem doenças crônicas como: hipertensão arterial, sequelas de acidente vascular cerebral, amputações e cegueiras causadas pelo diabetes, além da dependência causada por demências. Sendo assim, quando alcançada a terceira idade, a capacidade física do corpo humano sofre diversas alterações; e a redução da resistência e da força muscular são algumas delas. Relacionado a isso, entra o conceito de desenho universal, que desde o início da década de 1980 vem sido utilizado, o qual leva em consideração a capacidade funcional das pessoas relacionadas as barreiras ambientais. Isto é, quando soluções são criadas para que os espaços sejam utilizáveis por todos com independência e de forma confortável.

Segundo Cambiaghi (2012, p. 75), em um espaço acessível, todos os usuários podem ingressar, circular e utilizar todos os ambientes e não apenas parte deles. Isso devido ao propósito do desenho universal estabelecer acessibilidade integrada a todos, sejam essas pessoas com deficiência ou não. Portanto, deve-se disponibilizar os mesmos recursos de uso para todos; evitar segregar ou estigmatizar; disponibilizar privacidade, segurança e proteção de forma igualitária; fazer o produto atraente; oferecer adaptabilidade ao ritmo do usuário; uso simples e intuitivo; eliminar as complexidades; informação perceptíveis; dentre outros.

Do mesmo modo, utiliza-se as especificações da NBR 9050/2015, norma da Associação Brasileira de Normas Técnicas (ABNT), onde estabelece parâmetros técnicos a serem observados quanto ao projeto, construção, instalação e edificações às condições de acessibilidade, nos quais são consideradas diversas condições de mobilidade e percepção do ambiente, com ou sem ajuda de aparelhos específicos. Então, pode-se relacionar um ambiente como forma essencial para a melhoria da qualidade de vida e do bem-estar do usuário, garantindo o poder de desfrutar dos ambientes sem receber tratamento discriminatório por causa de suas características pessoais.

Ademais, os centros de convivência e habitação para idosos tem função de abrigar essas pessoas e que estas desenvolvam sentimentos pelo lugar que estão diretamente associadas e vivendo experiências, atribuindo o conceito de "ambiência". Melhor dizendo, é quando há consciência de que o corpo está vivenciando a sensação de pertencimento e inclusão em um espaço, onde poderá também aguçar os diversos sentidos (visão, tato, audição e olfato).

Outrossim, o Ministério da Saúde afirma que ao adotar o conceito de "ambiência" para arquitetura, alcança um avanço qualitativo no quesito da humanização dos territórios; onde determinados espaços, vivenciados por um grupo de pessoas expõem seus valores culturais e relações sociais. Ainda mais, que seja um espaço que vise a confortabilidade, valorizando elementos do ambiente que interajam com as pessoas (funcionários e usuários); produza subjetividade e seja utilizado como instrumento humanizado e acolhedor, para que contribua para o engajamento pessoal.

Portanto, esta pesquisa tem por finalidade apresentar resultados e sugestões relacionadas ao ambiente construído e ao processo projetual de locais em que haja a convivência e moradia de idosos, de modo que este recorte da população se sinta cada vez mais apta para socializar com outras pessoas em locais com conforto e bem-estar, promovendo oportunidades de lutarem contra o isolamento, criando laços sociais e de amizade; bem como a prática de atividades físicas e exercícios mentais. 


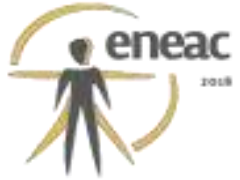

\section{REFERENCIAL TEÓRICO}

\subsection{Envelhecimento Ativo, Lazer e Atividade Física}

O reflexo da melhoria das condições de vida e humanização é o processo de envelhecimento populacional. Com relação às projeções das Nações Unidas (Fundo de Populações), 01 em cada 09 pessoas no mundo tem 60 anos ou mais, e há perspectiva que em torno de 2050, haja um crescimento de 01 para cada 05 pessoas. Idealiza-se, então, que esse número mais que duplique em 2050. De acordo com pesquisas do IBGE (Instituto Brasileiro de Geografia e Estatística), os idosos totalizam 23,5 milhões do total de brasileiros. Quando comparado 2009 e 2011, esse grupo aumentou 7,6\%.

Esses dados sobre o envelhecimento no Brasil levam a crer na política de saúde do envelhecimento ativo. Conforme a OMS (Organização Mundial da Saúde), desde o final dos anos 90, utiliza-se o termo "envelhecimento ativo", como processo de otimização das oportunidades de saúde, participação e segurança, com o objetivo de melhorar a qualidade de vida à medida que as pessoas ficam velhas. $O$ envelhecimento ativo pode ser aplicado tanto de forma grupal quanto individual, de maneira que possam compreender a sua capacidade para o bem-estar físico, mental e social ao longo da vida, com envolvimento dinâmico na sociedade.

O termo "ativo" não remete apenas à aptidão física, como também à atuação nas questões sociais, econômicas, culturais, espirituais e civis, cujo objetivo é aumentar a expectativa de vida salutar, com abarcamento de amigos, colegas de trabalho, membros da família. Por outro lado, o envelhecimento ativo necessita de uma série de determinantes, que são eles: comportamentais, pessoais, sociais, econômicos, o ambiente físico e serviços sociais e de saúde; os quais estimulam a saúde, socialização e segurança nos distintos âmbitos (ORGANIZAÇÃO PAN-AMERICANA DA SAÚDE).

Para isso, as políticas públicas atribuídas ao envelhecimento ativo fundamentam-se nos Princípios das Nações Unidas para Idosos, ou melhor, independência, assistência, autorrealização e dignidade. Essa estrutura está apoiada em três pilares básicos: saúde prevenir e reduzir a carga de deficiências em excessos; participação - propiciar educação e oportunidades de aprendizagem durante o curso da vida; e segurança - assegurar proteção e dignidade aos idosos, através dos direitos e necessidades de segurança social, financeira e física (ORGANIZAÇÃO PAN-AMERICANA DA SAÚDE).

Sendo assim, o lazer, além de contribuir para um melhor estado de espírito, ameniza os efeitos resultantes do processo de envelhecimento, bem como possui caráter educacional e de desenvolvimento da participação social. Também, o lazer e a recreação podem provocar a redescoberta da motivação, de sorte que envelhecer com saúde é um direito de cidadania (ROSA et al., 2014).

Além do envelhecimento ativo, lazer e recreação, pode-se citar a importância da atividade física atrelada à qualidade de vida dos idosos. A performance física se modifica com o passar dos anos, quando há prática de atividades físicas regularmente e adequadamente, com respeito as condições biológicas individuais, esses remodelamentos favorecem 0 prolongamento da vida, de maneira que reabilita as funções orgânicas interdependentes (MATTIELLO, Naiá et al., 2012).

O fato de selecionar as atividades físicas moldadas, ajuda a não desmotivar os idosos quando não conseguem realizar os exercícios propostos e não acarretar o abandono da prática. O corpo humano necessita ser movimento regularmente a fim de manter todas as funções sem limitações ou atrofiamento dos músculos. Assim, a atividade física regular e acompanhada, aumenta a resistência muscular e física, facilita a circulação sanguínea, 


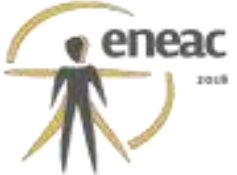

contribui positivamente para o retardo da fadiga e ajuda a regular os horários de sono. Por conseguinte, a prática de atividades físicas se destaca também na área psicossocial, pois diminui estresse, ansiedade, depressão; e, aumenta autoconfiança, autoestima e socialização.

Por fim, os programas de exercícios físicos conduzidos para a terceira idade, aliado a alimentação adequada, tem como desígnio subtrair a ocorrência de doenças crônicodegenerativas, doenças decorrentes do sedentarismo e prorrogar o surgimento de doenças limitadoras, como problemas de coordenação motora, nas articulações, no sistema respiratório, cardiovasculares, diabetes, obesidade, câncer, deterioração visual, enfraquecimento dos músculos. Sendo assim, torna-se possível aproveitar ao máximo a terceira idade, mostrando que o idoso está inserido com posição relevante na sociedade, capaz de possuir autonomia para exercer o seu papel de cidadão e manter as condições saudáveis e ativas.

\subsection{Desenho Universal e Acessibilidade}

A antropometria é um ramo da antropologia que estuda as medidas e dimensões das partes do corpo humano. Em 1956, foi inaugurada nos Estados Unidos a Human Factors Society, e nos anos 80, a organização iniciou o processo de medição de pessoas idosas, em detrimento do aumento dessa parcela populacional. Os dados levantados apontam para a redução de $5 \%$ a $6 \%$ da altura em relação à idade de 20 anos, além da piora da sensibilidade da visão, bem como a redução da força nos membros e enrijecimento das articulações, o que leva a dificuldade nos movimentos e dependências motoras (BESTETTI, 2006).

Desse modo, para uma velhice saudável, depende também da interação com o meio ambiente; essa dependência se sujeita à nuances como saúde, a posição socioeconômica, idade, raça, situação conjugal, apoio familiar, emprego, disponibilidade de transporte e residência, atividades e a integração social. Além da preocupação com o ambiente construído, por meio da utilização da legislação e normas técnicas (BESTETTI, 2006).

Posto isso, desde o início da década de 1980, o conceito de Universal Design (Desenho Universal) era discutido e analisado, sabendo que a capacidade funcional das pessoas era reduzida a partir da permanência das barreiras ambientais. Portanto, em um espaço acessível, todos os usuários podem ingressar, circular e utilizar todos os ambientes de maneira autônoma na sua máxima extensão (CARTILHA MINISTÉRIO PÚBLICO - SP).

Já em relação as normas técnicas de acessibilidade, estas servem de base para os estudos de adequações dos espaços para pessoas portadoras de algum tipo de deficiência. De acordo com a Organização Internacional de Estandardização (International Organization for Standardization - ISO), uma norma é "uma especificação técnica acessível ao público, aprovada por organismos de normalização, estabelecida com a cooperação e com o consenso de partes interessadas embasadas nos resultados conjuntos da ciência, da tecnologia e da experiência, tendo como objetivo conseguir benefício para a comunidade". Desse modo, as leis e normas para pessoas com deficiência afetam diretamente em ajustes arquitetônicos, seja através de rampas, elevadores ou banheiros adaptados (CAMBIAGHI, 2012).

No Brasil, as discussões acerca da acessibilidade também se iniciaram na década de 1980, a partir de um debate com o objetivo de conscientizar profissionais da área construtiva a respeito da importância de eliminar barreiras arquitetônicas aplicadas às pessoas com deficiência. Então, a partir de 1981, o Ano Internacional de Atenção à Pessoa Portadora de Deficiência, algumas leis foram publicadas a fim de regulamentar o acesso aos ambientes 


\section{(x) $^{\text {mane }}$}

construídos e garantir igualdade da parcela da população com deficiência ou mobilidade reduzida com os demais cidadãos (CAMBIAGHI, 2012).

Em 1985, foi elaborada a primeira lei relativa à acessibilidade, a NBR 9050, nomeada de "Acessibilidade a edificações, mobiliário, espaços e equipamentos urbanos à pessoa portadora de deficiência". Desde então, sofreu três revisões: a primeira em 1994, a segunda em 2004 e a terceira em 2015, que está em vigor atualmente. No entanto, para tornar esses parâmetros efetivos e adotados por profissionais, é necessário ampliar o espaço para pesquisa dos conceitos, não apenas levar em consideração uma legislação rígida.

Ainda assim, o Brasil dispõe de legislações amplas se tratando de acessibilidade e todas as leis brasileiras então vinculadas à NBR 9050, a qual é o principal instrumento de direção dos profissionais do ramo da construção civil. Portanto, pensar em ambientes acessíveis é estar de acordo com a segurança de todos, de tal forma a evitar incidentes, que, no caso dos idosos tratados nesse trabalho, estão vulneráveis e podem comprometer a rotina e a saúde, por meio da dependência e mudança de hábitos. Ou seja, é promover independência e qualidade para todos àqueles que usufruem de uma edificação, definida pelo respeito e valorização das diferenças existentes na sociedade.

\subsection{Ambiência e Humanização}

Ambiência, conforme a Cartilha de Ambiência criada pela Secretaria de Atenção à Saúde, Núcleo Técnico da Política Nacional de Humanização do Ministério da Saúde, dentro do programa nominado "HumanizaSUS" - também intitulado como Política Nacional de Humanização $(\mathrm{PNH})$ - concerne ao tratamento oferecido ao espaço no âmbito hospitalar, caracterizando-o como espaço social e ao criar circunstâncias vivenciadas por determinado grupo através de valores culturais e relações sociais. O conceito de ambiência direciona-se em três bases, as quais devem estar sempre unidas:

- O espaço focado na privacidade e individualidade, pretendido à confortabilidade e valorizando os elementos do ambiente onde há interação das pessoas, descritos na Tabela 01.

\section{Tabela 01 - Parâmetros da Ambiência}

\section{PARÂMETROS DE AMBIÊNCIA}

Morfologia

Luz
São as formas, volumes e dimensões que configuram espaços para serem adequados para as pessoas

lluminação natural ou artificial necessária para realização de atividades e que contribui para a organização de uma ambiência. Deve ser assegurada a noção de tempo - dia e noite, condições climáticas - pois pode influenciar no estado de saúde
Cheiro

Som

Sinestesia

\section{Ponderar odores que possam interferir no bem-estar dos usuários}

Proteção acústica para proporcionar privacidade e controle de ruídos

Percepção do espaço através de movimentos, das superfícies e texturas 


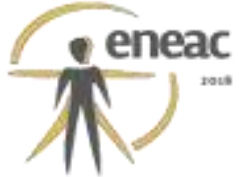

\begin{tabular}{ll}
\hline Arte & Inter-relação das sensações humanas \\
\hline Cor & $\begin{array}{l}\text { Estimular os sentidos (relaxamento, alegria, trabalho, movimento...) e } \\
\text { contribuição para conforto ambiental; }\end{array}$
\end{tabular}

Tratamento das Espaços de interação e convívio, onde também são incluídas áreas externas atividades físicas de relaxamento.

Fonte: Cartilha de Ambiência, adaptado pela autora.

- Subjetividade oportunizada através do espaço;

- O espaço utilizado como ferramenta para otimizar recursos, com atendimento humanizado.

Semelhantemente, a humanização está intrinsicamente ligada ao partido arquitetônico adotado durante o processo de planejamento. Esse planejamento concebe impactos no funcionamento, na estética do local, e nos reflexos psicológicos em detrimento dos ambientes. Em outras palavras, falar de ambiência também é declarar que não é formada somente pelo meio físico onde se vive, mas pelo efeito moral em que esse ambiente persuade no estado comportamental dos moradores. Similarmente, a humanização permite o resguardo e produção da subjetividade mais realista a partir de edificações que instiguem a socialização sem postergar a privacidade. Portanto, a conciliação desses conceitos, suscitou a compreensão dos inter-relacionamentos, onde soluções arquitetônicas fortificam acontecimentos confortáveis.

\section{NBR $9050 / 2015$}

A NBR 9050 é a norma brasileira que instrui parâmetros técnicos a serem observados no que tange ao projeto, construção, instalação e adaptação do meio urbano e rural, e de edificações às condições de acessibilidade. Esta norma tem como objetivo proporcionar a utilização de ambientes, edificações e mobiliários de forma autônoma, segura e independente, sem levar em consideração idade, estatura ou limitações de mobilidade ou percepção.

Desta maneira, são estabelecidas especificações para dimensionamento de calçadas e rebaixamento das guias; mobiliário urbano; acessos; sinalização em estacionamentos, portas, assentos fixos; tamanho de banheiros, sanitários e vestiários, bem como a instalação de suas peças e acessórios; dimensionamento de rampas, escadas, elevadores, plataformas elevatórias; tratamento de desníveis; afastamento entre obstáculos; aplicação de piso tátil de alerta e direcional; além de aspectos específicos a serem observados em estabelecimentos comerciais, locais de hospedagem e similares, restaurantes, serviços de saúde e de ensino.

Para esta pesquisa, com ênfase em idosos, será atentado, principalmente, para os seguintes aspectos:

- As calçadas devem possuir largura mínima de $1,20 \mathrm{~m}$, livre de qualquer obstáculo, com inclinação transversal de, no máximo, 3\%, e ser contínua entre lotes. A inclinação longitudinal necessita acompanhar sempre a inclinação das vias lindeiras. Apresentar o piso antiderrapante, regular, firme e não trepidante. Sobre os rebaixamentos de guia, estes carecem de se localizar somente em frente a faixa de pedestre, nas esquinas onde houver travessia de pedestre ou associada à vaga para 


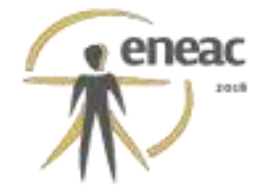

Pessoa Com Deficiência (P.C.D) em via pública.

- O estacionamento deve possuir $2 \%$ das vagas destinadas a pessoas com deficiência e mobilidade reduzida, com dimensões mínimas de 2,50m x 5,00m, ao lado de uma faixa de circulação livre de obstáculos de $1,20 \mathrm{~m}$ de largura. E, $5 \%$ das vagas destinadas a idosos. O percurso entre a vaga para P.C.D e o acesso à edificação ser de, no máximo, 50,00m. Essas vagas têm de possuir sinalização horizontal e vertical conforme as Resoluções 236/07, 303/08 e 304/08 do CONTRAN.

- As portas necessitam atender o vão livre mínimo de 0,80m e altura de 2,10m. Para portas de duas folhas, pelo menos uma delas deve possuir o vão livre de $0,80 \mathrm{~m}$. As maçanetas serem do tipo alavanca e o acionamento para abertura ter o formato de fácil pega. A sinalização deve estar localizada na faixa de alcance entre $1,20 \mathrm{~m}$ e $1,60 \mathrm{~m}$ em plano vertical; quando instalada nas portas, estar centralizada, sem conter informações táteis - para complementar essa informação, presença de informação tátil ou sonora, na parede adjacente a ela.

- Para circulação horizontal, haver afastamento mínimo de $0,80 \mathrm{~m}$ entre os obstáculos existentes no ambiente; e de 0,90m entre obstáculos com extensão superior a 0,40m. Os corredores serem de no mínimo: a) 0,90m para uso comum com extensão de até $4,00 \mathrm{~m}$; b) $1,20 \mathrm{~m}$ para uso comum com extensão de até $10,00 \mathrm{~m}$; c) $1,50 \mathrm{~m}$ para uso comum com extensão superior a 10,00m e corredores de uso público.

- Para a circulação vertical pode ser realizada por escadas, rampas ou equipamentos eletromecânicos, porém só é considerada acessível quando atende a, no mínimo, duas formas de deslocamento.

- As rampas devem possuir a largura mínima de 1,50m, com inclinação máxima de 8,33\%; faixa de piso tátil de alerta no início e término; corrimão com alturas de $0,70 \mathrm{~m}$ e $0,92 \mathrm{~m}$, com prolongamento de $0,30 \mathrm{~m}$ antes do início e após o término e seção circular entre $3,0 \mathrm{~cm}$ e $4,5 \mathrm{~cm}$, respeitando o afastamento mínimo de $4 \mathrm{~cm}$ entre a parede e o corrimão. No caso de ausência de paredes laterais, haver guarda-corpo com altura de $1,05 \mathrm{~m}$ e guia de balizamento com altura mínima de $5 \mathrm{~cm}$.

- As escadas devem possuir o piso entre $0,28 \mathrm{~m}$ e $0,38 \mathrm{~m}$; a altura do espelho entre $0,16 \mathrm{~m}$ e $0,18 \mathrm{~m}$ (não pode ter o espelho vazado); largura mínima de $1,20 \mathrm{~m}$; faixa de piso tátil de alerta no início e término; corrimão com alturas de 0,70m e 0,92m, com prolongamento de $0,30 \mathrm{~m}$ antes do início e após o término e seção circular entre $3,0 \mathrm{~cm}$ e $4,5 \mathrm{~cm}$, respeitando o afastamento mínimo de $4 \mathrm{~cm}$ entre a parede e o corrimão. No caso de ausência de paredes laterais, haver guarda-corpo com altura de $1,05 \mathrm{~m}$ e guia de balizamento com altura mínima de $5 \mathrm{~cm}$.

- Os elevadores devem oferecer acesso a todos os pavimentos; cabine com dimensões mínimas de 1,10m x 1,40m; haver espelho ou vidro para que permita que o usuário de cadeira de rodas observe obstáculos enquanto se move para trás ao sair do elevador; corrimão fixado nos painéis laterais e de fundo, com altura entre $0,85 \mathrm{~m} e$ 0,90m; possuir piso tátil de alerta distando, no máximo, $0,32 \mathrm{~m}$ da porta do elevador.

- As plataformas elevatórias devem atender a dimensão mínima de 0,90m 1,40m, com entrada livre mínima de 0,90m; existir corrimão localizado em altura entre $0,90 \mathrm{~m}$ e $1,10 \mathrm{~m}$ do piso, em lado que não seja o de entrada da plataforma; os dispositivos operacionais localizados em uma região entre $0,80 \mathrm{~m}$ e $1,10 \mathrm{~m}$ do piso; símbolo internacional de acesso (SIA) em todas as portas da plataforma.

- No caso, tratando-se de edificação de uso coletivo construída a partir de 11 de outubro de 2015 (data em que a norma entrou em vigor), deve dispor de 5\% de sanitários acessíveis, com no mínimo um com entrada independente em cada pavimento, nos locais onde houver sanitários - sendo necessário cobrar em mais de 


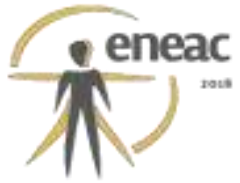

um local quando a distância entre eles for superior a $100 \mathrm{~m}$. Seguindo as seguintes dimensões (Figura 01):

Figura 01 - Vista superior das medidas mínimas de um sanitário acessível.

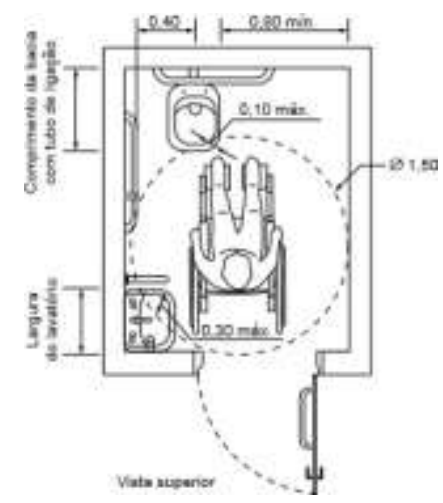

Fonte: NBR 9050/2015

- O sentido de abertura da porta ser para fora, com puxador horizontal afixado na parte interna com comprimento de $0,40 \mathrm{~m}$, distando $0,90 \mathrm{~m}$ do piso acabado e $0,10 \mathrm{~m}$ da dobradiça.

- Possuir dispositivo de sinalização de emergência a $0,40 \mathrm{~m}$ de altura, próximo à bacia sanitária, no boxe do chuveiro e na banheira.

- Bacia sanitária sem abertura frontal, com altura de, no máximo, 0,46m na borda superior com assento. Barras de apoio horizontais e verticais.

- Lavatório com altura entre 0,78m e 0,80m, dotado de barras horizontais e verticais. Torneiras acionadas por alavanca, sensor eletrônico ou dispositivo equivalente. Tratando-se de bancada com vários lavatórios, as barras de apoio devem estar posicionadas pelo menos em uma das extremidades.

- O mictório deve possuir barras de apoio com afastamento de 0,60m, comprimento mínimo de $0,70 \mathrm{~m}$, fixadas com altura inferior de $0,75 \mathrm{~m}$; acionamento de descarga com altura de até $1,00 \mathrm{~m}$.

- O boxe do chuveiro deve possuir a dimensão mínima de 0,90m x 0,95m. Apresentar banco com profundidade mínima de $0,45 \mathrm{~m}, 0,46 \mathrm{~m}$ de altura e comprimento mínimo de $0,70 \mathrm{~m}$; dispor de barras de apoio horizontais e verticais; o registro do chuveiro ser do tipo alavanca e fixado a $1,00 \mathrm{~m}$ do piso acabado, distando $0,85 \mathrm{~m}$ da parede na qual se encontra o banco; o chuveiro ser equipado com desviador para ducha manual.

- Os acessórios (saboneteira, toalheiro) atenderem à altura entre 0,80m e 1,20m; o espelho acima de lavatórios com borda inferior a no máximo $0,90 \mathrm{~m}$ e borda superior com no mínimo $1,80 \mathrm{~m}$ de altura; espelho em paredes sem lavatório com borda inferior a no máximo 0,50m e borda superior com no mínimo 1,80m de altura.

- Os boxes comuns de sanitários coletivos necessitam apresentar portas com vão livre mínimo de 0,80m e área livre com no mínimo 0,60m de diâmetro; distância de, no mínimo, 0,60m entre a bacia sanitária e a porta (quando aberta); lavatórios dotados de barras de apoio.

- Haver oferta de mesas para utilização de PCD na quantidade mínima de 5\%, com no mínimo uma, com altura entre $0,75 \mathrm{~m}$ e $0,85 \mathrm{~m}$; altura livre inferior de, no mínimo, 0,73m; largura mínima de 0,80m; avanço mínimo de 0,50m para o usuário da mesa e 


\section{(x) $^{\text {remax }}$}

avanço mínimo de 0,30m para o interlocutor.

- Os armários devem atender à altura de utilização entre $0,40 \mathrm{~m}$ e $1,20 \mathrm{~m}$ do piso acabado.

- Balcão de atendimento com altura de $0,75 \mathrm{~m}$ a $0,85 \mathrm{~m}$, com altura livre de $0,73 \mathrm{~m}$ e $0,90 \mathrm{~m}$ de extensão; além de avanço de $0,30 \mathrm{~m}$, em um espaço mínimo com largura de 0,80m para aproximação de Pessoa de Cadeira de Rodas (P.C.R.).

- Existir 5\%, com no mínimo 01 (um) assento para Pessoa Obesa (P.O.) e com no mínimo 01 (um) espaço para Módulo de Referência (M.R.) com assento ao lado para acompanhante, sem interferir na faixa livre de circulação; bem como estar sinalizado com o SIA.

Para locais de hospedagem e similares, deve haver pelo menos $10 \%$, com no mínimo 01 do total de dormitórios com sanitário, adaptado para utilização por P.C.D ou com pessoas com mobilidade reduzida. Seguindo as seguintes dimensões (Figura 02):

\section{Figura 02 - Vista superior da área de circulação mínima de um dormitório acessível}

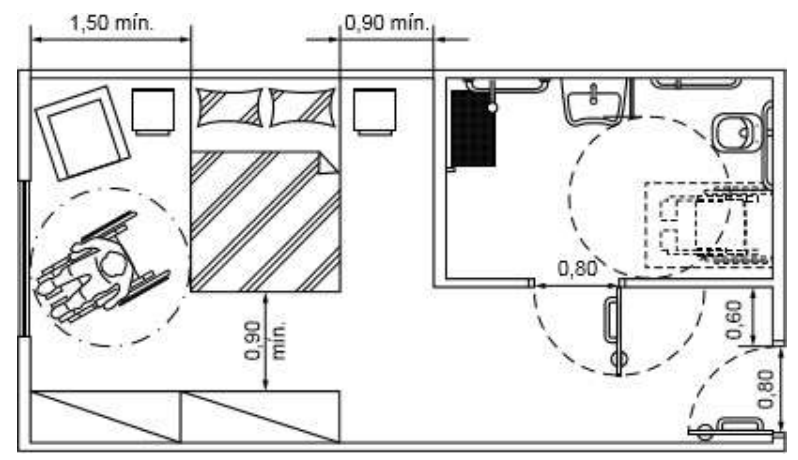

Fonte: NBR 9050/2015

Por fim, para as piscinas, o piso do entorno deve ter acabamento arredondado e não escorregadio. $\mathrm{O}$ acesso à água deve ser garantido através de degraus, rampas submersas, banco para transferência ou equipamentos de transferência. $E$, onde houver ducha, no mínimo uma deve garantir o acesso de pessoa em cadeira de rodas.

\section{ANÁLISES E RESULTADOS}

Diante dos conceitos e dos estudos baseados na NBR 9050/2015 relacionados à convivência e habitação para idosos, realizou-se visitas técnicas com a finalidade de observar as necessidades dos moradores, visitantes e funcionários; a disposição dos ambientes de acordo com especificado na norma técnica; bem como as atividades oferecidas nestes locais e funcionamento delas.

Dessa forma, pôde-se notar que embora na grande maioria dos locais destinados a atividades de pessoas da terceira idade tenha intenção de ajustes da edificação conforme os parâmetros estabelecidos na norma de acessibilidade, ainda não a atendem plenamente, principalmente no tocante aos banheiros, circulação e sinalizações. No entanto, quando se trata da grade de atividades, há uma preocupação em ofertar exercícios físicos e manuais, com a intenção de manter a saúde corporal e mental dos frequentadores. 


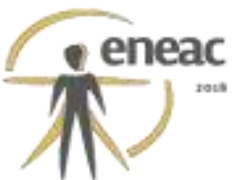

Sendo assim, foi analisado algumas das maiores irregularidades e as atividades em funcionamento que contribuem para o processo de envelhecimento ativo e inclusão social. Como exemplo de irregularidades, cita-se banheiros com as barras de apoio instaladas em desacordo com o estabelecido na norma técnica, falta de alarme de emergência, torneira sem comando acessível, dentre outros (Figura 03). Além disso, a presença de desníveis sem tratamento adequado no decorrer da circulação horizontal, como no caso abaixo, é possível identificar um desnível vencido através de rampa sem corrimãos, guarda-corpo associado, guia de balizamento e faixa de piso tátil de alerta antes do início e após o término da mesma (Figura 04).

\section{Figura 03 - Porta com vão livre inferior a $0,80 \mathrm{~m}$ e sinalização sem atender aos padrões da norma técnica.}

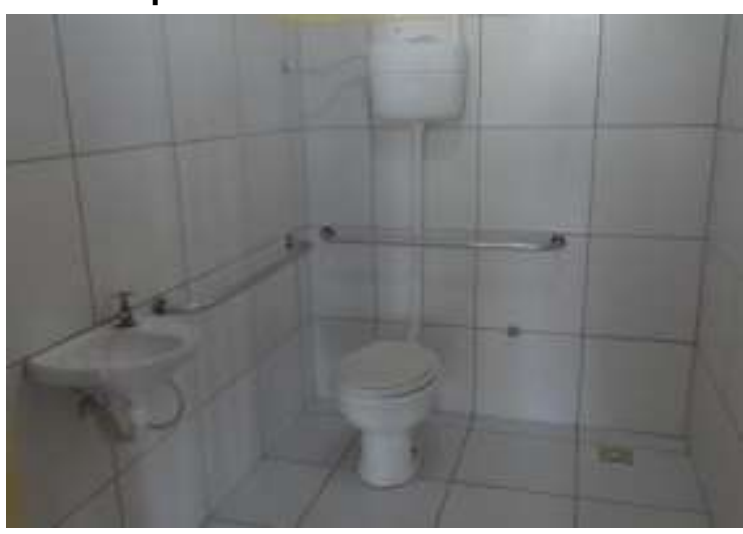

Fonte: Acervo da autora, 2017.
Figura 04 - Desnível vencido através de rampa em desacordo com a NBR $9050 / 2015$.

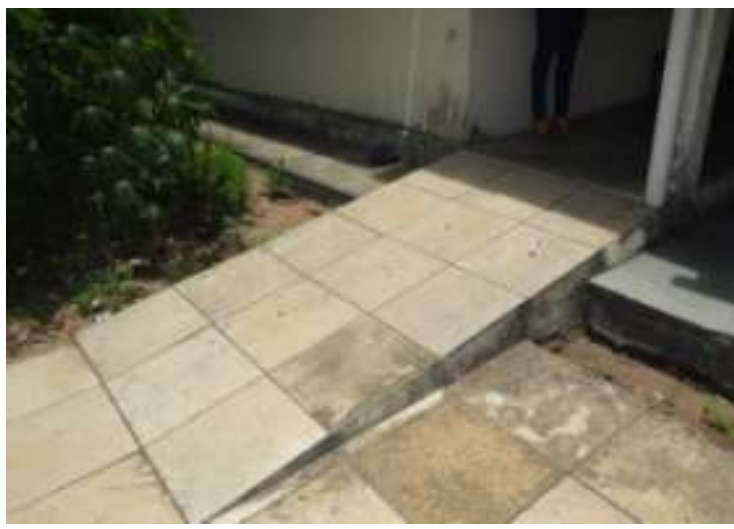

Fonte: Acervo da autora, 2017.

Ainda se tratando das irregularidades, algumas portas possuem vão livre inferior ao mínimo exigido de $80 \mathrm{~cm}$, além de não haver sinalização visual e tátil conforme a norma técnica (Figura 05). Ademais, desníveis sem tratamento adequado comprometem a livre circulação nos ambientes, além de apresentar o piso trepidante (Foto 06).

Figura 05 - Porta com vão livre inferior a $80 \mathrm{~cm}$ e sinalização fora do padrão.

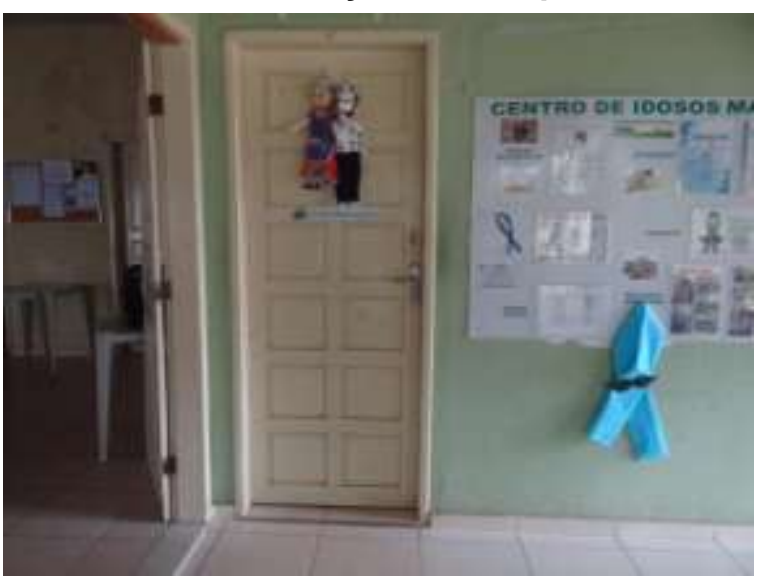

Fonte: Acervo da autora, 2016.
Figura 06 - Desníveis sem tratamento adequado.

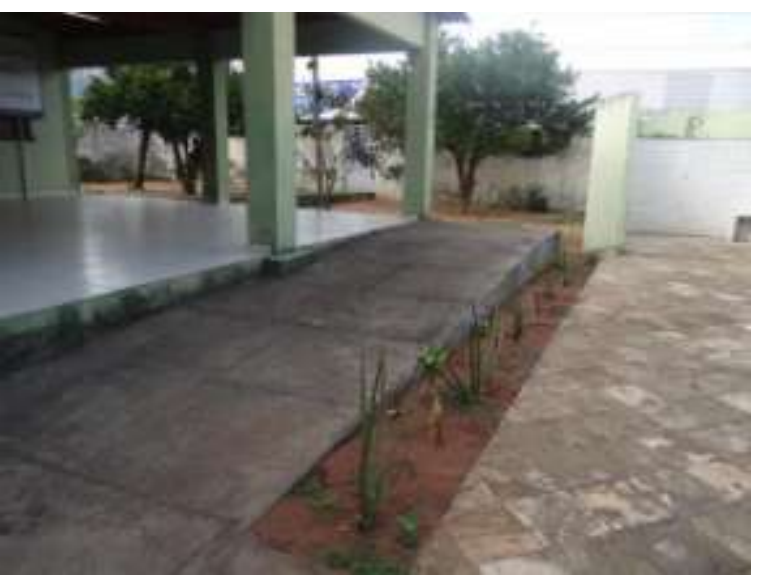

Fonte: Acervo da autora, 2016. 


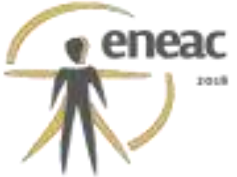

Já com relação as atividades físicas e recreativas oferecidas, na grande maioria trata-se de artesanato, pintura, aula de música, costura, computação, hidroginástica e dança. Porém, os locais realizados e acessos para essas atividades não atendem aos conceitos de desenho universal e acessibilidade, como no caso das mesas abaixo (Figura 07) e o acesso para a piscina (Figura 08).

Figura 07 - Mesas não permitem aproximação de usuário

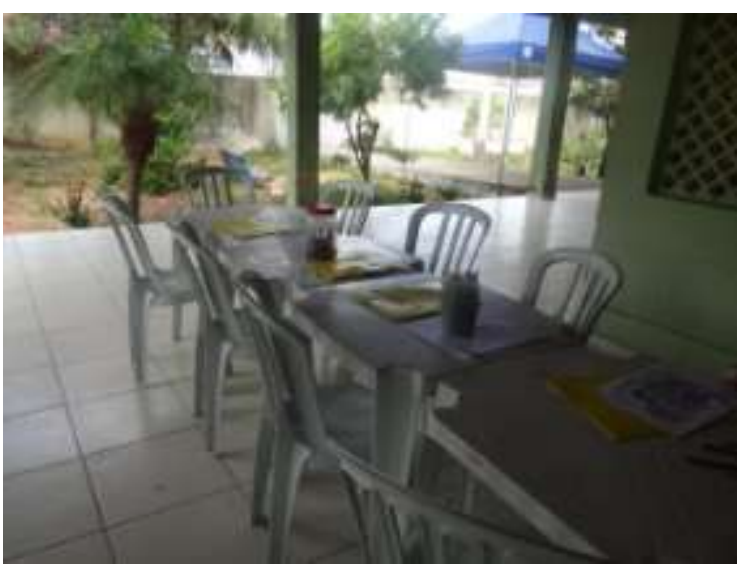

Fonte: Acervo da autora, 2016.
Figura 08 - Acesso para a piscina com uma combinação de escada com rampa

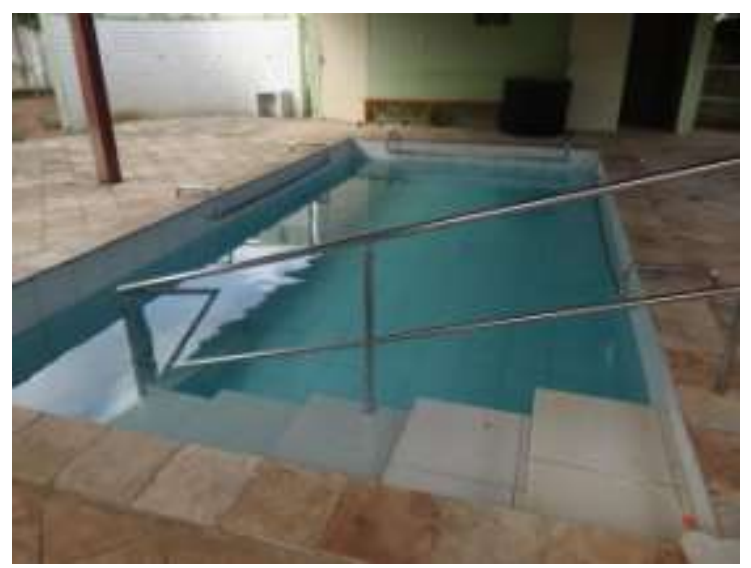

Fonte: Acervo da autora, 2016.

\section{CONSIDERAÇÕES FINAIS}

A partir dos estudos conceituais e das análises realizadas em algumas edificações destinadas ao uso de idosos, percebeu-se a carência de espaços que incorporem plenamente o estabelecido com a norma regulamentada (NBR 9050), para oferecer acessibilidade aos usuários. Além disso, com os estudos realizados acerca do envelhecimento no Brasil, pôde-se notar a promessa para o demasiado crescimento de idosos para os próximos anos, associado aos conceitos de envelhecimento ativo e acessibilidade, o que influencia diretamente no modo de vida atual da sociedade.

Dessa forma, notou-se a necessidade de ambientes que possam abranger habitação, atividades de lazer e saúde, auxiliando na redução de doenças predominantes nas pessoas acima de 60 anos, como por exemplo, depressão, obesidade, problemas cardíacos e respiratórios; bem como na contribuição de socialização, autonomia para realização de atividades básicas da rotina, contato familiar e, tratando-se de estrutura, a aplicação de normas que são os principais parâmetros para edificações as quais lidam com idosos.

Portanto, após essa série de análises que respaldaram o desenvolvimento desse artigo, com a finalidade de auxiliar positivamente na qualidade de vida dessa fração populacional, observou-se que, para garantir o envelhecimento salutar da geração atual, antes de tudo, deve possibilitar o usufruto dos espaços sem receber tratamento discriminatório devido suas características pessoais, de modo a reduzir a distância funcional entre os elementos dos ambientes e as capacidades das pessoas, aliado ao processo de realização de atividades físicas e mentais que contribuam para a rotina regular. 


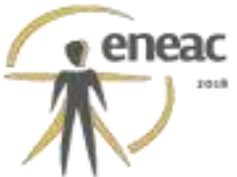

\section{REFERÊNCIAS}

ASSOCIAÇÃO BRASILEIRA DE NORMAS TÉCNICAS. NBR 9050: Acessibilidade a edificações, mobiliário, espaços e equipamentos urbanos. Rio de janeiro, 2015. 148 p.

ASSOCIAÇÃO NACIONAL DOS SERVIDORES PÚBLICOS, DA PREVIDÊNCIA E DA SEGURIDADE SOCIAL. População idosa deve triplicar até 2050. 2016. Disponível em: <https://www.anasps.org.br/populacao-idosa-deve-triplicar-ate-2050/>. Acesso em: 7 mar 2017.

BESTETTI, Maria Luiza Trindade. Habitação para Idosos. O trabalho do arquiteto, arquitetura e cidade. São Paulo, FAU USP, 2006. 184f. Doutorado (Tese) - Programa de Pós graduação. Faculdade de Arquitetura e Urbanismo. Universidade de São Paulo, São Paulo, 2006.

BRASIL. Ministério da Saúde. Secretaria de Atenção à Saúde. Núcleo Técnico da Política Nacional de Humanização. Ambiência / Ministério da Saúde, Secretaria de Atenção à Saúde, Núcleo Técnico da Política Nacional de Humanização. - 2. ed. - Brasília: Editora do Ministério da Saúde, 2006. 32 p. - Série B. Textos Básicos de Saúde.

CAMBIAGHI, Silvana. Desenho Universal: métodos e técnicas para arquitetos e urbanistas / Silvana Cambiaghi; [ilustrações de André Ypussef]. - 3aㅡ ed. Ver. - São Paulo: Editora SENAC São Paulo, 2012.

MATTIELLO, Naiá et al. Importância da atividade física para a terceira idade. Lecturas, Educación Física y Deportes: Revista Digital. Buenos Aires. Ano 17, № 170. Jul. 2012. Disponível em: <http://www.efdeportes.com/efd170/atividade-fisica-para-a-terceira-idade.htm>. Acesso em: 19 abr 2017.

ROSA, Juliana Garcia da et al. Lazer e Recreação dos Idosos em Instituições de Longa Permanência. 2014. Disponível em: <http://www.unifia.edu.br/>. Acesso em: 15 abr 2017.

SÃO PAULO (Estado). Ministério Público. Cartilha Desenho Universal. Habitação de interesse social. Disponível em: <http://www.mpsp.mp.br/portal/page/portal/Cartilhas/manual-desenhouniversal.pdf>. Acesso em: 4 mai 2017.

SOCIEDADE BRASILEIRA DE GERIATRIA E GERONTOLOGIA. Envelhecimento no Brasil e Saúde do Idoso: SBGG divulga carta aberta à população. Rio de Janeiro, 2014. Disponível em: $<$ http://sbgg.org.br/envelhecimento-no-brasil-e-saude-do-idoso-sbgg-divulga-carta-aberta-apopulacao-2/>. Acesso em: 7 mar 2017. 